\title{
Editorial
}

\section{APROXIMACIONES A LA GEOSINERGIA PARAGLACIAL}

El término paraglacial fue conceptualizado primeramente por CHURCH \& RYDER (1972), quienes lo aplicaron a procesos y patrones geomorfológicos relacionados con climas glaciales. Posteriormente, RENWICK (1992) observó que la activación glacial deja como herencia un tiempo de relajación significativo, con mecanismos de ajuste que pueden llevar a condiciones inestables en las geosinergias. Pero una revisión de investigaciones en los dominios periglacial, glacio-fluvial, glacio-marino, glacio-lacustre y sistemas complejos asociados, llevó a BALLANTYNE (2002) a proponer que el campo de la geomorfología paraglacial incluye procesos, sistemas de formas y paisajes condicionados por una glaciación anterior y la consecuente deglaciación. Esta conceptualización conduce a una renovación metodológica, que puede traducirse en una aproximación geosinergética entre dominios asociados. El enfoque paraglacial, como idea central de análisis, fue aplicado por primera en Chile en una cuenca andina de Chile Central y en un análisis integrado entre formas subaéreas y submarinas del Canal Beagle (Magallanes), como proxi de mecanismos de ajuste paraglacial en un paleo-fiordo (ARAYA-VERGARA 2008 y 2011).

Apreciando la importancia de estos enfoques en un país como Chile, en el presente volumen de Investigaciones Geográficas se muestra los análisis de tres tipos de hechos que convergen en el gran dominio paraglacial. El primero trata de fenómenos asociados directamente con la operación glacial inmediata en un lugar de la costa antártica e integrando el medio glaciomarino con el proglacial de recesión, en un conjunto de operaciones de la dinámica actual y del Holoceno Reciente. El segundo se refiere a fenómenos de movimientos en masa ligados a condiciones morfoclimáticas patagónicas y a rupturas de equilibrio en vertientes heredadas de mecanismos periglaciales. El tercero apunta a la producción de rupturas de fondo de fiordo sobre materiales heredados de la morfogénesis en la última Glaciación y en el Holoceno. En estas contribuciones se advierte la interacción entre el gran dominio paraglacial y factores externos, expresados en irregularidades pluviométricas presentes, forzamiento co-sísmico e impactos volcánicos. Así, estos fenómenos fronterizos, comúnmente infrecuentes, indican inestabilidad geosinergética que hace posible la investigación de la frecuencia y la intensidad de los tipos de ruptura.

\section{REFERENCIAS}

ARAYA-VERGARA, J.F., 2008. Geomorfología glacial y paraglacial en la cuenca andina del Mapocho, Andes de Santiago, Chile. Invest. Geogr. Chile, 40: 21-48.

ARAYA-VERGARA, J.F., 2011. Relaciones entre formas glaciales sub-aéreas y paraglaciales submarinas en el Canal Beagle. En : Comité Oceanográfico Nacional-Chile (Ed.), Crucero Cimar 16-Fiordos, Informes Preliminares. CONA, Valparaíso, pp. 271-279.

BALLANTYNE, C.K. (2002) Paraglacial Geomorphology. Quaternary Science Reviews, 21, 19352017.

CHURCH, M. \& J. M. Ryder, 1972. Paraglacial Sedimentation: A Consideration of Fluvial Processes Conditioned by Glaciation. GSA Bull., 83(10): 3059-3072.

RENWICK, W.H., 1992. Equilibrium, disequilibrium, and nonequilibrium landforms in the landscape. Geomorphology, 5: 265-276. 